\section{FUNCTIONAL EVALUATION OF CEMENTED BIPOLAR HEMIARTHROPLASTY IN UNSTABLE INTERTROCHANTERIC FRACTURE FEMUR: A PROSPECTIVE STUDY}

\section{Original Article Orthopaedics}

Santosh L. Munde ${ }^{1}$, Varun Gautam ${ }^{2}$, Anil Kumar Gulia ${ }^{3}$, Sanjiv Kumar ${ }^{4}$, Dhruv Sharma $^{5}$, Ashish Kumar Arya ${ }^{6}$

${ }^{1}$ - MS Professor, Dept. of Orthopaedics, KC Govt. Medical College, Karnal

2 - DNB PG, Dept. of Orthopaedics, BPS Govt. Medical College, Khanpur Kalan, Sonipat

${ }^{3}$ - Associate Professor, Dept. of Orthopaedics, BPS Govt. Medical College, Khanpur Kalan, Sonipat

${ }^{4}$ - MS Assisstant Professor, Dept. of Orthopaedics, BPS Govt. Medical College, Khanpur Kalan, Sonipat

${ }^{5}$ - MS Assisstant Professor, Dept. of Orthopaedics, BPS Govt. Medical College, Khanpur Kalan, Sonipat

${ }^{6}$ - DNB PG, Dept. of Orthopaedics, BPS Govt. Medical College, Khanpur Kalan, Sonipat

Article submitted on: 05 January 2019 Article Accepted on: 19 January 2019

\begin{abstract}
Objective: Osteosynthesis with internal fixation devices are the most commonly performed operations for intertrochanteric fractures of hip. However osteosynthesis of an intertrochanteric fracture does not allow early weight bearing. This observational, prospective study was conducted to study the functional outcome of cemented bipolar hemiarthroplasty in unstable intertrochanteric femur fracture in elderly age group.

Methods: A prospective study was conducted on 20 patients of elderly age group with intertrochanteric fracture femur Boyd and Griffin type 2 or more and others according to the inclusion criteria. The functional outcome was measured by Harris hip score at 6 months after cemented bipolar hemiarthroplasty in these patients.

Results: The mean age was 77.10 years. Majority of the patients were osteoporotic with $90 \%$ patients falling into Singh's index grade III, II, I. $60 \%$ were type II and $40 \%$ were type IV Boyd and Griffin intertrochanteric fracture. The average operative time was 81.25 minutes. All t patients were trained to begin walking with a walker at a mean of 2.30 days with $85 \%$ of the patients ambulated successfully. The mean Harris hip score at the 6th month follow up was $75.30 \pm 27.22$ with $p$ value as 0.00 I. Excellent to fair results were seen in $75 \%$ of the patients.
\end{abstract}

Keywords: Intertrochanteric fracture femur, cemented bipolar hemiarthroplasty 


\section{Introduction}

Conservative treatment of intertrochanteric fracture femur resulted in poor anatomical and functional outcome, lesser certainty of union, delayed ambulation, difficult nursing, bed sores, foot drop, deep venous thrombosis and consequent increased mortality. ${ }^{1}$

Most intertrochanteric fracture patients have severe osteopenia and this along with comminution render internal fixation difficult and early ambulation of the patient is difficult. In addition comminution along calcar and posterior cortex leads to varus malpositioning of fracture fragments. ${ }^{2}$ The dynamic hip screw and proximal femoral nail have been commonly used for internal fixation of intertrochanteric fractures with good to excellent results but the failure rate of unstable intertrochanteric fractures with internal fixation devices with osteoporosis has been reported to be between $3 \%$ and $16.5 \%{ }^{3}$ The failure rate of the dynamic hip screw is $6.8 \%$ to $9.8 \%$ while failure rate of the proximal femoral nail is between $7.1 \%$ to $12.5 \%{ }^{4}$ Cutting out of the DHS implant from the femoral head continues to be an important cause of mechanical failure though its incidence is determined by factors like fracture subtype, quality of reduction, implant position and bone density. ${ }^{5}$ An intramedullary device (gamma nail) has some theoretical advantage over DHS and its predecessors. It is not dependent on screw fixation of a plate to the lateral cortex, which can be a problem in very osteoporotic bone. In addition, as the load is transmitted to the femur along a more medial axis, it has a short moment arm. ${ }^{5}$ With unstable intertrochanteric fractures, internal fixation achieves satisfactory initial fracture site reduction but late fracture collapse into varus during weight bearing especially in osteopenic individuals can lead to high failure rates. ${ }^{6}$

In search for immediate postoperative stability of the bone implant complex, primary prosthetic replacement with cement offers a relatively new method of treating intertrochanteric fractures. This technique allows early ambulation to avoid complications of prolonged recumbency. Arthroplasty per se is absolved of the fracture site nonunion and avascular necrosis. ${ }^{7}$ Adititionally ,a hip prosthesis allows early full weight bearing, and thereby expedites the patient's return to preinjury functional level.

We conducted a study to evaluate the role of cemented bipolar hemiarthroplasty in unstable intertrochanteric femur fractures.

\section{Materials and Methods}

After obtaining approval from the Institutional Ethics committee and written informed consent, a prospective study was conducted on 20 patients of elderly age group with intertrochanteric fracture femur at BPS Government Medical College, Khanpur Kalan between February 2017 to November 2018.

Inclusion criteria were patients with Intertrochanteric fracture femur Boyd and Griffin type 2 or more, elderly patients with non-united intertrochanteric fracture femur and patients with failed internal fixation of intertrochanteric fracture femur. Exclusion criteria were undisplaced or minimally displaced fracture, Boyd and Griffin type 1,subtrochanteric fracture femur and open fractures.

A complete history of mode of injury, duration of trauma and preinjury ambulatory status was recorded along with the comorbid conditions. In local examination, the deformity, disability, distal neurovascular status, soft tissue injuries and other associated injuries were recorded. Anteroposterior views of pelvis with both hips and lateral view of the involved hip were taken. All the necessary routine investigations required for pre anaesthetic check up were done

Patients were given perioperative antibiotic prophylaxis. Surgery was done under spinal or general anaesthesia combined with epidural in lateral position. Posterolateral approach was used, fixed cemented bipolar prosthesis was used in all cases. The medullary canal of the femur was made accessible and rasped with progressively increased sized broach. To ensure neutral implant alignment, the broach was directed towards the medial femoral condyle. If the greater trochanter was intact, a part of its medial cortex was removed to avoid varus malalignment. Anteversion was ensured by directing the medial aspect of broach towards the floor by $15-20$ degrees while the leg was held flexed and perpendicular to the floor by an assistant .The prosthetic trial was done and stability of reduction, limb length was checked. The centre of prosthesis was taken at the tip of trochanter. In cases where the greater trochanter was fractured, the length determination was done by repositioning the fractured greater trochanter anatomically and observing the tension in the fascia over the gluteus medius. After acceptable trial fit, the head was redislocated and the trial was removed.

If calcar was found to be deficient, calcar was reconstructed with a cut autograft from the femoral neck or cement. The permanent prosthesis was cemented into the femoral canal at a proper level and the constructed calcar 
was compressed between collar of the femoral stem and proximal femur as the stem is fully inserted. If greater trochanter was found fractured, it was reattached to the proximal femur with tension band wiring or encirclage wiring.

Patients were mobilized with full weight bearing with the support of walker as soon as patient's condition permitted starting from $2^{\text {nd }}$ postoperative day. A walker was used for at least six weeks, followed by a cane if the patient had adequate muscle strength and balance.

\section{Follow up}

The patients were evaluated at 2 weeks, 6 weeks, 3 months, 6 months and at each follow up functional evaluation of the patient was done to note the range of movements at hip and knee, limb length discrepancy, dislocation and sinking of prosthesis and signs of loosening. Results were assessed using Harris Hip Score.

\section{Statistical Analysis}

The data was entered into a Microsoft Excel spreadsheet and analysed using standard statistical software SPSS $^{\circledR}$ statistical package version 22. For continuous outcome mean \pm SD was calculated and for categorical outcome, proportion and percentage were calculated. Categorical variables were analysed using Chi square test and for continuous outcomes student $-\mathrm{t}$ test was used. $p$ value $<0.05$ was considered as statistically significant.

\section{Results}

The mean age was 77.10 years and range was 70 to 95 years. $70 \%$ of the patients were in the age group of 70-80 years and $30 \%$ patients were in the age group of above 80 years.

$57.2 \%$ of the male subjects and $76.9 \%$ of the female subjects were in $70-80$ years of age group. $42.8 \%$ of the male subjects and $23.1 \%$ of the females were in the age group of above 80 years.

$60 \%$ of the subjects had an unstable intertrochanteric fracture on the right side and $40 \%$ had it on the left side.

Table 1: Distribution of subjects according to Boyd and Griffin fracture classification $^{8}$

\begin{tabular}{|l|c|c|}
\hline $\begin{array}{c}\text { Fracture } \\
\text { classification }\end{array}$ & Frequency & Percentage \\
\hline Type II & 12 & $60 \%$ \\
\hline Type IV & 8 & $40 \%$ \\
\hline Total & 20 & 100 \\
\hline
\end{tabular}

Grading of osteoporosis (according to Singh's Index9)

Table 3: Descriptive characteristics of surgery and hospital stay of patients

\begin{tabular}{|c|c|c|c|c|}
\hline Variable & \multirow{2}{*}{$\begin{array}{c}\text { Range } \\
60-100 \\
\min \end{array}$} & \multicolumn{2}{|c|}{ Mean (Median) } & $\begin{array}{l}\text { Standard } \\
\text { deviation }\end{array}$ \\
\hline $\begin{array}{l}\text { Duration of surgery (in } \\
\text { minutes) }\end{array}$ & & 81.25 & $(80.00)$ & 10.86 \\
\hline Post-operative stay (in days) & 5-20 days & 7.95 & $(7.00)$ & 3.85 \\
\hline Full weight bearing (in days) & 2-4 days & 2.30 & $(2.00)$ & 0.571 \\
\hline $\begin{array}{l}\text { Duration between admission } \\
\text { and surgery at hospital (in } \\
\text { days) }\end{array}$ & 1-8 days & 4.75 & $(4.50)$ & 1.61 \\
\hline
\end{tabular}

Analysis of the patients according to Harris Hip Score

Table 4: Distribution of patients according to Harris Hip Score 10 at follow ups

\begin{tabular}{|l|c|c|}
\hline \multicolumn{1}{|c|}{ Time of measurement } & Mean & Standard deviation \\
\hline 2 weeks & 33.35 & 7.21 \\
\hline 6 weeks & 43.45 & 16.50 \\
\hline 3 months & 60.60 & 22.54 \\
\hline 6 months & 75.30 & 27.22 \\
\hline
\end{tabular}

ANOVA test, $p$-value $=0.001$

The above table depicts the distribution of patients according to Harris Hip Score at follow ups. The mean Harris hip score at 2 weeks was 33.35 , at 6 weeks 43.45 , at 3 months 60.60 and at 6 months it was 75.30 .
Figure 1: Bar diagram depicting distribution of patients according to Harris Hip Score at various interval

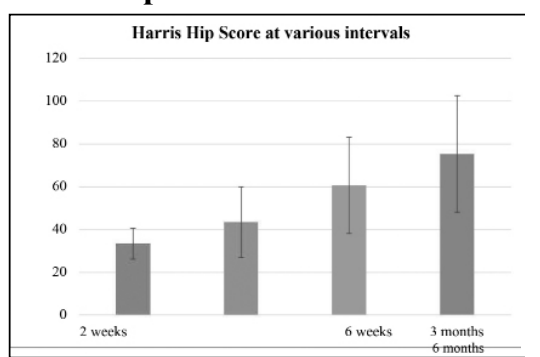

Final outcome of the study subjects at 6th month follow up 
Table 5: Final outcome of subjects at 6 month follow up according to Harris Hip Score

\begin{tabular}{|l|c|c|}
\hline $\begin{array}{c}\text { Harris } \\
\text { Hip Score } \\
\text { grade }\end{array}$ & Frequency & Percentage \\
\hline Excellent & 6 & $30 \%$ \\
\hline Good & 7 & $35 \%$ \\
\hline Fair & 2 & $10 \%$ \\
\hline Poor & 2 & $10 \%$ \\
\hline Dead & 3 & $15 \%$ \\
\hline
\end{tabular}

The above table depicts the distribution of subjects at 6 months according to Harris Hip Score. 30\% patients had an excellent outcome, $35 \%$ had a good outcome, the outcome was fair in $10 \%$ patients and poor in $10 \%$ of the patients at the end of 6 months. $15 \%$ patients died during the study duration.

Figure 2: Pie diagram depicting the distribution of subjects at 6 months according to Harris Hip Score

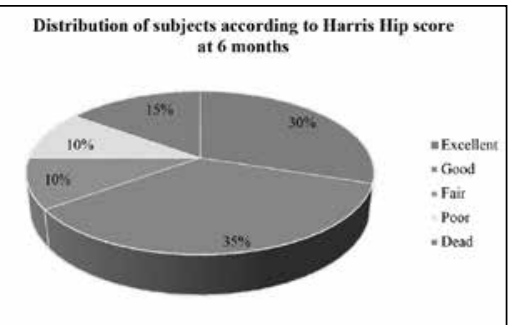

\section{Discussion}

Intertrochanteric femur fractures are associated with substantial morbidity and mortality, about 30\% of elderly patients die within 1 year and many more experience significant functional loss. ${ }^{11}$ Around more than $50 \%$ of all intertrochanteric femur fracture are unstable with comminution of posteromedial cortex. ${ }^{3}$

Although arthroplasty in unstable fractures presents greater challenge to surgeon and may require calcar reconstruction or reattachment of fragments using encirclage wires but the complications like nonunion, malunion, metal breakage or impingement are of no concern with the prosthesis.

Tronzo claimed to be the first to use long, straight stemmed prosthesis for the primary treatment of intertrochanteric fractures. ${ }^{12}$ Rosenfeld and Schwartz, reported good results with the use of the Leinbach prosthesis. ${ }^{12}$ Rodop et al in a study of primary bipolar hemi arthroplasty for unstable intertrochanteric fractures in 37 elderly patients obtained 17 excellent (45\%) and $14 \operatorname{good}(37 \%)$ results after 12 months according to the Harris hip scoring system. ${ }^{4}$

The average age of the patients in our study is 77.10 years. The high incidence of intertrochanteric fractures in elderly population reflects high incidence of osteoporosis in these patients.

Comorbidity in the aged patients further complicates the management of these fractures. The comorbid illnesses did delay the surgical fitness of the patients, thereby resulting in some delay in surgery. One of the patients with pre-existing diabetes and hypertension developed postoperative wound infection which later on led to septicaemia and renal failure and she expired in the postoperative period. One of the patients with pre-existing hypertension developed cardiac insufficiency and expired after 6 weeks of surgery.

Table 6 and 7 shows comparision of different variables of our study with other studies.

Table 6: Comparision of different variables of our study with other studies

\begin{tabular}{|l|c|c|c|c|}
\hline \multicolumn{1}{|c|}{ Variables } & Sancheti KH et al. & Kim YS et al. ${ }^{\mathbf{1 4}}$ & Shen J et al. $^{\mathbf{1 5}}$ & Present study \\
\hline Number of Patients & 37 & 46 & 60 & 20 \\
\hline Mean age (years) & 77.10 & 79.70 & 78.2 & 77.10 \\
\hline No. of female patients & 27 & 41 & 47 & 13 \\
\hline No. of male patients & 10 & 5 & 13 & 7 \\
\hline Average operative time & $71 \mathrm{~min}$ & $90 \mathrm{~min}$ & - & $81.25 \mathrm{~min}$ \\
\hline Mean Blood transfused(units) & 1.0 & 3.0 & & $\begin{array}{c}1.20 \pm 0.410 \mathrm{units} \\
(420 \pm 143.63 \mathrm{ml})\end{array}$ \\
\hline Average hospital stay(days) & 10.96 & 26.50 & & 7.95 \\
\hline $\begin{array}{l}\text { Mean of Weight bearing } \\
\text { started(days) }\end{array}$ & 3.2 & 13.6 & & 2.30 \\
\hline
\end{tabular}

Table 7: Comparision of different variables of our study with other studies

\begin{tabular}{|c|c|c|c|c|}
\hline Variables & Gashi YN et al. ${ }^{16}$ & Mansukhani SA et al. ${ }^{17}$ & Park BJ et al. ${ }^{18}$ & Present study \\
\hline $\begin{array}{l}\text { Percentage of cases with history of } \\
\text { fall }\end{array}$ & 96.70 & 100 & & 100 \\
\hline $\begin{array}{l}\text { Mean duration between admission } \\
\text { and surgery }\end{array}$ & & & 3.6 days & 4.75 days \\
\hline Incidence rate of dislocation & $1.7 \%$ & $18.2 \%$ & & $0 \%$ \\
\hline
\end{tabular}


The delay in surgery was mostly on account of time required for stabilization of general condition of the patients so as to make them fit for anaesthesia and surgery.

Cemented bipolar hemiarthroplasty was done in 20 patients diagnosed with unstable intertrochanteric fractures. The calcar was constructed by the bone cement or the autograft taken from the femoral neck. This was done to prevent sinking of prosthesis. In 4 of the patients tension band wiring was done for the fractured greater trochanter and in 7 of the patients encirclage wires were used to reattach greater and lesser trochanter.

In our study $85 \%$ of the patients were successfully ambulated after the surgery. $50 \%$ of the patients maintained good ambulatory status, $25 \%$ had dependency on walking aids but were successfully mobile while $10 \%$ of the patients who were initially ambulated successfully had a poor outcome at the end of the study.

One patient developed post operative wound infection subsequently leading to death, two other patients who were ambulated initially died of cardiopulmonary arrest at 6 weeks and 3 months respectively.

In the final follow up, $75 \%$ patients had no pain and $20 \%$ had slight pain. In one patient the implant was in varus malposition which might be causing slight pain. In other three patients the cause of slight pain could not be detected but the probable cause of pain might be due to altered biomechanics of hip due to limb length discrepancy, impingement of $\mathrm{K}$ wires in the soft tissues where tension band wiring for fractured greater trochanter was done, trochanteric bursitis as the bursa might not have been excised completely during the surgery.

Harris Hip score was used in our study for assessing the final outcome of patients. The total score is 100 , with outcome graded as excellent, good, fair and poor. The mean Harris hip score at 6th month follow up was $75.30 \pm 27.22$ with $p$ value as

0.001 which is comparable with the previous studies:

\begin{tabular}{|l|c|}
\hline \multicolumn{1}{|c|}{ Authors } & $\begin{array}{c}\text { Mean Harris } \\
\text { hip score at } \text { 6 }^{\text {th }} \\
\text { month follow up }\end{array}$ \\
\hline Park BJ et al. $^{18}$ & 73.20 \\
\hline Singh S et al. $^{19}$ & 78.33 \\
\hline Shen J et al. $^{15}$ & 76.50 \\
\hline Present study & 75.30 \\
\hline
\end{tabular}

In our study excellent to fair results were seen in $75 \%$ of the patients which is comparable with the previous studies:

\begin{tabular}{|l|c|}
\hline \multicolumn{1}{|c|}{ Authors } & $\begin{array}{c}\text { Cases with } \\
\text { excellent to fair } \\
\text { results }\end{array}$ \\
\hline $\begin{array}{l}\text { Mansukhani } \\
\text { SA et al. }{ }^{17}\end{array}$ & $90 \%$ \\
\hline Pal CP et al. ${ }^{20}$ & $71.50 \%$ \\
\hline $\begin{array}{l}\text { Sancheti KH et } \\
\text { al. }{ }^{13}\end{array}$ & $91 \%$ \\
\hline Present study & $75 \%$ \\
\hline
\end{tabular}

In conclusion, given the few complications and comparable functional recovery in this small study we believe that primary cemented hemiarthroplasty offers a modality of treatment that provides adequate fixation and early mobilization in these patients, thus preventing postoperative complications such as pressure sores, pneumonia, atelectasis, and pseudo arthrosis. Delays in the surgeries are one of the most important predictor of mortality in patients with intertrochanteric fractures and also of the postoperative morbidity.

Limitations of our study were small sample size and shorter duration of follow up.

\section{References}

1. Murray RC, Frew JF. Trochanteric fractures of the femur. The Journal of bone and joint surgery. British volume. 1949 May;31(2):204-19.

2. Rao JP, Banzon MT, Weiss AB, Rayhack JO. Treatment of unstable intertrochanteric fractures with anatomic reduction and compression hip screw fixation. Clinical orthopaedics and related research. 1983 May (175): 65-71.

3. Abdelkhalek M, Ali AM, Abdelwahab M. Cemented bipolar hemiarthroplasty with a cerclage cable technique for unstable intertrochanteric hip fractures in elderly patients. European Journal of Orthopaedic Surgery \& Traumatology. 2013 May 1;23 (4):443-8.

4. Pal CP, Mittal V, Sharma B, Sadana A, Singh M, Hussain A. Functional Outcome of Hemiarthroplasty in Unstable Intertrochanteric Femur Fracture in Elderly Patients. Journal of Bone and Joint Diseases| Jan. 2016;31.

5. Butt MS, Krikler SJ, Nafie S, Ali MS. Comparison of dynamic hip screw and gamma nail: a prospective, randomized, controlled trial. Injury. $1995 \mathrm{Nov}$ 1;26(9):615-8.

6. Green S, Moore T, Proano F. Bipolar prosthetic replacement for the management of unstable intertrochanteric hip fractures in the elderly. Clinical orthopaedics and related research. 1987 Nov (224):169-77.

7. Pho RW, Nather A, Tong GO, Korku CT. Endoprosthetic replacement of unstable, comminuted intertrochanteric fracture of the femur in the elderly, osteoporotic patient. The Journal of trauma. 1981 Sep; 21(9):792-7. 
8. Boyd HB, Griffin LL. Classification and treatment of trochanteric fractures. Archives of Surgery. 1949 Jun 1;58(6):85366.

9. Singh M, RIGGS BL, Beabout JW, Jowsey J. Femoral trabecularpattern index for evaluation of spinal osteoporosis. Annals of internal medicine. 1972 Jul 1;77 (1): 63-7.

10. Mahomed NN, Arndt DC, McGrory BJ, Harris WH. The Harris hip score: comparison of patient self-report with surgeon assessment. The Journal of arthroplasty. 2001 Aug 1; 16 (5): 575-80.

11. Tang $\mathrm{P}$, Hu F, Shen J, Zhang L, Zhang L. Proximal femoral nail antirotation versus hemiarthroplasty: a study for the treatment of intertrochanteric fractures. Injury. 2012 Jun 1;43(6):876-81.

12. Maru N, Sayani K. Unstable intertrochanteric fractures in high risk elderly patients treated with primary bipolar hemiarthroplasty: retrospective case series. Gujarat Med J. 2013;68(2):68-72.

13. Sancheti KH, Sancheti PK,
Shyam AK, Patil S, Dhariwal Q, Joshi R. Primary hemiarthroplasty for unstable osteoporotic intertrochanteric fractures in the elderly: Aretrospective case series. Indian journal of orthopaedics. 2010 Oct; 44(4):428.

14. Kim YS, Hur JS, Hwang KT, Choi IY, Kim YH. The comparison of compression hip screw and bipolar hemiarthroplasty for the treatment of AO Type A2 intertrochanteric fractures. Hip \& pelvis. 2014 Jun 1;26(2):99-106.

15. Shen J, Wang DL, Chen GX, Li L, Wei MX, Cai XQ, Yu ZH, Cheng L, Zhang XX, Zou TM, Yang HL. Bipolar hemiarthroplasty compared with internal fixation for unstable intertrochanteric fractures in elderly patients. Journal of Orthopaedic Science. 2012 Nov 1;17(6):722-9.

16. Gashi YN, Elhadi AS, Elbushra IM. Outcome of Primary Cemented Bipolar Hemiarthroplasty compared with Dynamic Hip Screw in Elderly Patients with Unstable Intertrochanteric Fracture. Malaysian orthopaedic journal. 2018 Mar; 12 (1):36.
17. Mansukhani SA, Tuteja SV, Kasodekar VB, Mukhi SR. A Comparative study of the Dynamic Hip Screw, the Cemented Bipolar Hemiarthroplasty and the Proximal Femoral Nail for the Treatment of Unstable Intertrochanteric Fractures. Journal of clinical and diagnostic research: JCDR. 2017 Apr; 11(4): RC 14.

18. Park BJ, Cho HM, Min WB. A comparison of internal fixation and bipolar hemiarthroplasty for the treatment of reverse oblique intertrochanteric femoral fractures in elderly patients. Hip \& pelvis. 2015 Sep 1;27(3):152-63.

19. Singh S, ShrivaStava C, Kumar S. Hemi replacement arthroplasty for unstable inter-trochanteric fractures of femur. Journal of clinical and diagnostic research: JCDR. 2014 Oct;8(10):LC01.

20. Pal CP, Mittal V, Sharma B, Sadana A, Singh M, Hussain A. Functional Outcome of Hemiarthroplasty in Unstable Intertrochanteric Femur Fracture in Elderly Patients. Journal of Bone and Joint Diseases| Jan. 2016;31. 